\title{
Total Mesorectal Excision Technique-Past, Present, and Future
}

\author{
Joep Knol, MD ${ }^{1}$ Deborah S. Keller, MS, MD² \\ ${ }^{1}$ Department of Abdominal Surgery, Jessa Hospital, Hasselt, Belgium \\ ${ }^{2}$ Division of Colorectal Surgery, NewYork-Presbyterian/Columbia \\ University Medical Center, New York, New York \\ Address for correspondence Joep Knol, MD, Department of \\ Abdominal Surgery, Jessa Hospital, Hasselt, Belgium \\ (e-mail: joep.knol@jessazh.be).
}

Clin Colon Rectal Surg 2020;33:134-143.

\begin{abstract}
While the treatment of rectal cancer is multimodal, above all, a proper oncological resection is critical. The surgical management of rectal cancer has substantially evolved over the past 100 years, and continues to progress as we seek the best treatment. Rectal cancer was historically an unsurvivable disease, with poor understanding of the embryological planes, lymphatic drainage, and lack of standardized technique. Major improvements in recurrence, survival, and quality of life have resulted from advances in preoperative staging, pathologic assessment, the development and timing of multimodal therapies, and surgical technique. The most significant contribution in advancing rectal cancer care may be the standardization and widespread implementation of total mesorectal excision (TME). The TME, popularized by Professor Heald in the early

Keywords

- rectal cancer

- total mesorectal excision (TME)

- transanal total mesorectal excision (TaTME)

- holy plane

- mesorectal fascia 1980 s as a sharp, meticulous dissection of the tumor and mesorectum with all associated lymph nodes through the avascular embryologic plane, has shown universal reproducible reductions in local recurrence and improvement in disease-free and overall survival. Widespread education and training of surgeons worldwide in the TME have significantly impact outcomes for rectal cancer surgery, and the procedure has become the gold standard for curative resection of rectal cancer. In this article, we discuss the evolution of the standard abdominal approach to the TME, with emphasis on the history, relevant anatomy, standard procedure steps, oncologic outcomes, and technical evolution.
\end{abstract}

\section{Enhanced Reader Experience}

This article is dynamic with Video-In-Picture technology. Please download the VIPicture application for iPhone or Android to link images in this paper to a video or 3D model. To do so, open the VIPicture application on your smart device by searching for "VIPicture" in the App store (iPhone) or Google Play store (Android). Subsequently, allow your phone to access your camera. This will activate the camera within the application to recognize the image within the manuscript, thereby linking you to the appropriate video or 3D model. Images that qualify for use with the application can be identified by the presence of the "VIP" or "VIP-3D" logo.

\section{Historic Management of Rectal Cancer}

"All carcinomas of the lower sigmoid and upper rectum are tabooed by all practical surgeons on account of their anatomical inaccessibility. All are abandoned without hope to linger on for a few months until death relieves them of their loathsome condition." H. W. Maunsell, The Lancet, 1892

The surgical management of rectal cancer has substantially evolved over the past 100 years, and continues to progress as we seek the best treatment. Rectal cancer was historically an unsurvivable disease, with a poor understanding of the
Issue Theme Transanal Total Mesorectal Excision; Guest Editors: Dana Sands, MD, FACS, FASCRS, and Steven D. Wexner, MD, PhD (Hon), FACS, FRCS (Eng), FRCS (Ed), FRCSI (Hon), Hon FRCS (Glasg)
Copyright $\odot 2020$ by Thieme Medical Publishers, Inc., 333 Seventh Avenue, New York, NY 10001, USA. Tel: +1(212) 760-0888.
DOI https://doi.org/ 10.1055/s-0039-3402776. ISSN 1531-0043. 
embryological planes, lymphatic drainage, and a lack of standardized technique. In the early twentieth century, patients underwent a perineal proctectomy as the standard of care, with poor oncologic outcomes and high morbidity. The first moves to improve surgical outcomes and standardize surgery for rectal cancer came from Dr. William Ernest Miles in 1908. Recognizing the rampant recurrent disease and mortality after the perineal proctectomy, Miles investigated and found tissue later termed mesorectum left in the pelvis, with the lymphovasculature and mesorectal nodes by the iliac vessels; he called these areas, "zones of upward spread," and designed an operation to include the mesorectum and its contents-the abdominoperineal resection (APR). ${ }^{1,2}$ With the APR, Miles advocated for combined abdominal and perineal resections to ensure completed resection of the mesorectum and clearance of the "zones of upward spread." The abdominal resection entailed dissection of the rectum, mesorectum, and colostomy creations, and the perineal resection encompassed dissection and detachment of the anorectum and levator complex from the ischiorectal fat and pelvic organs. ${ }^{3}$ Miles found the APR reduced the recurrence rate from almost $100 \%$ to approximately $30 \%$, with benefits limited from the use of blunt dissection. ${ }^{4}$ His recognition of the necessity to remove the mesorectum in its entirety laid the groundwork for the modern total mesorectal excision (TME) and continued improvement of the curative rectal cancer resection. In his resection, Miles proposed a low tie ligature of the inferior mesenteric artery (IMA); however, there was controversy over what the best level of arterial ligation and division should be in a radical rectal resection. Sir Berkeley George Andrew Moynihan advocated for a high vascular tie ligature and division to complete the lymphadenectomy, stating that surgery of malignant disease is really surgery of the lymphatic system, not solely the organs, the concept used today. ${ }^{5}$ In efforts to reduce complications and mortality rates after the APR, in 1921, Henri Hartmann introduced the anterior resection of the rectum with a sigmoid colostomy on the left flank, which preserved the distal third of the rectum and the anal sphincters. ${ }^{6}$ While there was less morbidity and mortality with the "Hartmann procedure," patients still had a permanent stoma, and proximal rectal tumors were the primary indication for this procedure. Better surgical technology was needed to completely resect lower rectal cancers and restore continuity. Other techniques for radical proctectomy and proctectomy with sphincter preservation were detailed by Dixon, Habr-Gama, Bacon and Giambalvo, and Black, but lacked the standardization in technique and widespread use of the APR. ${ }^{7-11}$ The restorative low anterior resection (LAR) gained popularity with data from Goligher et al that local tumor spread in rectal cancer did not exceed $2 \mathrm{~cm}$ from tumor margins in most cases, and that a distal resection margin (DRM) of $5 \mathrm{~cm}$ was sufficient for radical resection at that time. ${ }^{12}$ The safe margin for a proper oncologic resection has since been advocated as $2 \mathrm{~cm}$ below the level of the distal margin or $1 \mathrm{~cm}$ for cancers located at or below the mesorectal margin or after neoadjuvant chemoradiotherapy. ${ }^{13}$ The development of surgical staples in the 1970s, specifically the circular intraluminal stapler, were a technology breakthrough which made a lower anastomosis universally technically possible, with anastomotic leak rates with the stapler similar to that of hand-sewn anastomoses. ${ }^{14,15}$ The double stapling technique accelerated creation of the low colorectal anastomoses for a restorative LAR, even in a narrow, fixed pelvis, minimizing issues in joining bowel segments of different sizes and intraoperative contamination. ${ }^{16}$ This new technology made the technical portions of the TME feasible, and permitting further development of the procedure.

\section{Introduction of the Total Mesorectal Excision}

Major improvements in recurrence, survival, and quality of life have resulted from advances in preoperative staging, pathologic assessment, the development and timing of multimodal therapies, and surgical technique. ${ }^{11}$ However, the most significant contribution in advancing rectal cancer care may be the standardization and widespread implementation of TME.

The concept of the TME and description of the anatomy and procedure dates far back before the modern era. The first known description of the mesorectal concept was by Romanian surgeon and anatomist Thoma Jonnesco in 1896, which he called "la gaine fibreuse du rectum." ${ }^{17}$ While Jonnesco did not use the term "mesorectum," he described the rectum as encapsulated within this thin fibrous sheath, which separated it from the other pelvic organs and allowed the rectum to be mobilized from the sacrum without damaging the presacral vessels. ${ }^{17,18}$ In 1899, Wilhelm Waldeyer described the fascia propria recti, referencing Jonnesco's original observations, and adding his own observations on the lack of anterior peritoneal component of the fascia. ${ }^{18,19}$ Waldayer's description of the perirectal fascia and its components was translated and published by Crapp and Cuthbertson in their 1974 article "The Book Shelf-William Waldeyer and the Rectosacral Fascia."20 These concepts were incorporated into the TME procedure, which was first described by Abel in $1931 .^{21}$ However, Professor Richard (Bill) Heald popularized and promoted the TME. ${ }^{22}$ TME removes the rectal cancer with its primary lymphovascular drainage as an intact package, by deliberate dissection under direct vision along embryologically determined planes between visceral and parietal structures, which preserves the autonomic nerves required for the maintenance of urinary and sexual function (-Fig. 1) ${ }^{23}$ Heald's insight was that rectal cancer is more apt to spread along the field of active lymphatic and venous flow, not distally along the muscular tube. He described that lymphatic extension of a rectal cancer created a "danger zone" in the mesorectum around the visible and palpable tumor, and that incomplete and variable resection of this "danger zone" might explain the extraordinarily wide variation in reported local recurrence rates. ${ }^{24} \mathrm{He}$ described the proper surgical plane as the potential space along the avascular interface between the mesorectum and the surrounding somatic structures-the holy plane-which could be reproducibly created by dissection. ${ }^{24}$ The importance of a proper TME in the "holy plane" is essential, as the plane of surgery achieved remains the main prognostic factor for recurrence. ${ }^{25,26}$ Pairing better surgical technology with his formal approach to proctectomy, widespread training, and implementation, Heald revolutionized the way we manage rectal cancer, 


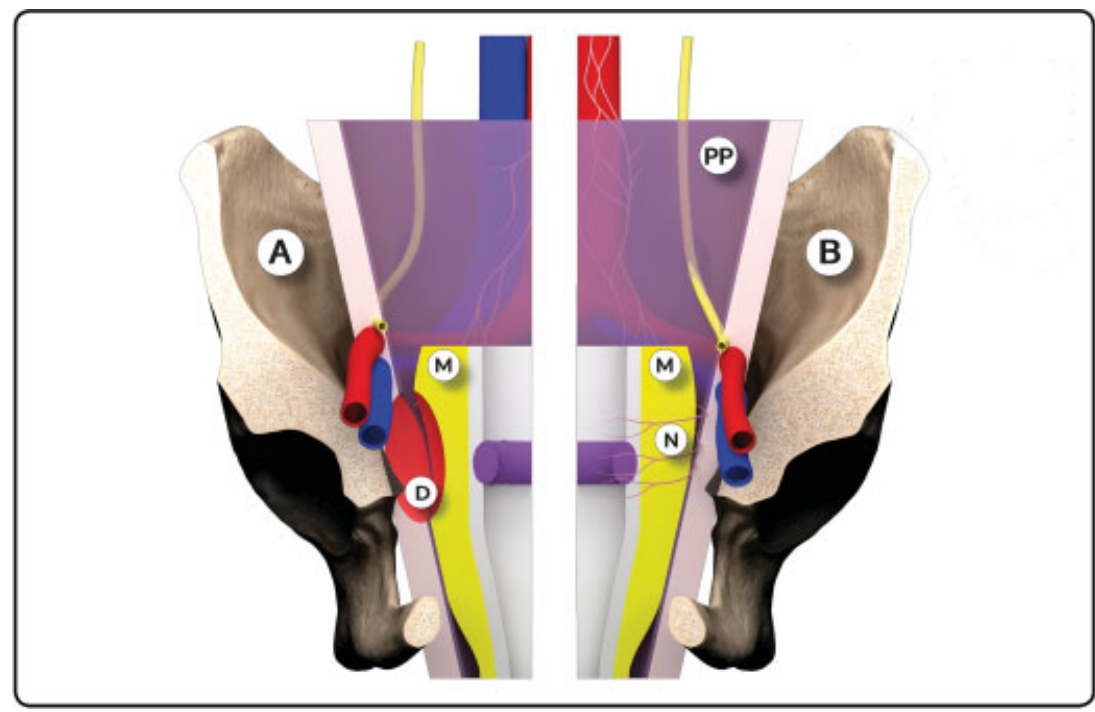

Fig. 1 Three-dimensional model: Anatomic state before total mesorectal excision (TME) (A); risk of defect (D) in mesorectum (M) and parietal peritoneum (PP). Anatomic state after introduction of TME (B): intact mesorectum (M) and nerve-sparing resection (N) (Use VIPicture App).

standardizing the teaching and training, significantly reducing recurrence, and improving survival, making the TME the gold standard for curative rectal cancer surgery worldwide. ${ }^{22,27-34}$ Heightened awareness of the proper surgical techniques has created much interest in the anatomy involved in TME surgery, with particular focus on the fascial planes and their relationship to the surgical planes of excision. ${ }^{35}$

\section{Relevant Embryology and Anatomy of the TME Planes}

\begin{abstract}
"My personal story is of gradual realization that this midline gut tube can be redefined with its intrinsic lymphovascular surround as a midline envelope recognizable for surgeons by the spider's web of areolar tissue around it. The distal part of the envelope is around the rectum and becomes the mesorectum, and the cobweb around it where the surgeon dissects is the 'holy plane'. The key hypothesis was that each part of the envelope, if very carefully removed en bloc, might have a very good chance of enveloping the whole primary field of spread of a cancer and thus curing all but the most advanced cases."

Richard J. Heald, Manual of Total Mesorectal Excision, 2013
\end{abstract}

A proper TME is inextricably linked with anatomy and embryology. The rectum is a hollow muscular tube located at the end of the large intestine, where the epiploic appendages are absent and the taeniae coalesce to form a complete lineal muscular layer. Although not anatomically distinct, the rectum is segmented into upper $(12-15 \mathrm{~cm})$, $\mathrm{mid}(7-12 \mathrm{~cm})$, and lower rectal divisions $(0-7 \mathrm{~cm})$ from the anal verge; the rectum is actually variable in length, but these approximate divisions are important when considering surgical treatment of rectal cancer. $^{36}$ The majority of the rectum is extraperitoneal, although anteriorly and laterally the upper rectum is covered by a layer of visceral peritoneum down to the peritoneal reflec- tion. ${ }^{36}$ The peritoneal reflection lies approximately 7 to $9 \mathrm{~cm}$ from the anal verge anterior, but its location is also highly variable and can be affected by gender and different disease states. $^{37}$ The embryological hindgut mesentery is the mesorectum, connective tissue, and fat housing the vascular and lymphatic supply ensheathed by a fascial system. The embryologic fascial structures of the pelvis define the anatomy and surgical planes of dissection, provide support, and may direct and limit the spread of malignant disease. Heald's TME principles were based on the knowledge that the fascial plane surrounding the mesorectum-the mesorectal fascia-is created by a separate embryological origin from the rectum and mesorectum, which have the same embryological origin and are one distinct lymphovascular entity (-Fig. 2). ${ }^{38}$ As the embryological delineation of the visceral from the somatic individuum, the mesorectal fascia confers protection against tumor dissemination and confines the main route of rectal cancer spread. An avascular, areolar tissue plane lies between the mesorectal fascia and the parietal pelvic fascia. Appropriate traction on the mesorectal fascia during surgery exposes this potential space, defined as the "holy plane." Meticulous, sharp dissection along this embryological plane will enable an oncologically safe and complete removal of the rectal cancer with minimal neurovascular damage or impact on urinary or sexual function. It also serves as a histopathological landmark for comparison of quality of surgical resection. ${ }^{23}$ The bulk of the mesorectum is posterior to the rectum, seen as two protruding bulges (the "mesorectal cheeks"). It tapers at the anorectal junction, and extending the surgical dissection plane downward around mesorectal fascia passes within the puborectalis sling into the space between the external and internal anal sphincters. ${ }^{23}$ Anteriorly, the mesorectum is thin and bordered by Denonvilliers' fascia, a tough fibrous, doublelayered tissue that separates the extraperitoneal rectum anteriorly from the prostate and seminal vesicles in men or the posterior vaginal wall in women. ${ }^{39}$ In females, Denonvilliers' fascia is less developed and the anterior mesorectum less 




Fig. 2 Embryological development of the gastrointestinal tract (Use VIPicture App).

substantial. ${ }^{36}$ Study has shown that Denonvilliers' fascia is more closely applied to the prostate than the rectum, and lies anterior to the anatomic fascia propria plane in anterior rectal dissection. ${ }^{40}$ The pelvis is supported by the endopelvic fascia, which has two components: the visceral layer (fascia propria of the rectum), a thin, transparent layer that lines the rectum and maintains the integrity of the mesorectum, and a parietal layer (presacral fascia), which runs posterior to the mesorectum follows the concavity of the sacrum to cover the presacral veins and hypogastric nerves. The presacral fascia extends caudally to the anorectal junction covering the anococcygeal ligament and laterally to cover the piriformis muscle and upper coccyx, then becomes continuous with the fascia propria of the rectum, contributing to the lateral ligaments of the rectum. During a proper TME, the fascia propria is elevated sharply off of the presacral fascia, which is left intact. Leaving the presacral fascia intact reduces the risk of exposing the highpressure presacral veins, a potential source of severe bleeding during the mobilization of the rectum. ${ }^{41}$ Inferiorly, between the levels of the third and fourth sacral vertebra, the mesorectum and the presacral fascia fuse to form the retrosacral fascia or Waldeyer's fascia. Waldeyer's fascia serves as an anchoring fascia of the rectum, and extends anteriorly to join the posterior layer of the fascia propria proximal to the anorectal junction. ${ }^{20}$ This layer is surgically relevant during posterior rectal mobilization because it must be sharply divided to release the surrounding areolar tissue plane and for its close relationship to the sympathetic hypogastric nerves and the inferior hypogastric plexus. ${ }^{42}$ Improper dissection can lead anteriorly to breach of the mesorectum and posteriorly to tearing of the prefascia, with bleeding from the presacral veins. The lateral ligaments of the rectum are trapezoid structures originating from the mesorectum and anchored to the endopelvic fascia at the level of the midrectum. Heald did not describe these ligaments in his description of the TME. ${ }^{27}$ They do not contain middle rectal arteries or nerve structures of importance, but the urogenital bundle runs just above the lateral ligament at its point of insertion on the endopelvic fascia, the middle rectal artery runs posterior to it, and the nervi recti fibers from the inferior hypogastric plexus course transversely under the lateral ligament to the rectal wall ${ }^{43}$; thus, being mindful of these relationships is important during a pelvic dissection. At the most distal part of the rectum, the mesorectum thins out and is virtually absent. Distal rectal cancers are thus at greater risk of invading surrounding structures at this level. A proper pelvic T2-weighted magnetic resonance imaging (MRI) is invaluable to demonstrate the important anatomic landmarks, such as the mesorectal fascia, presacral and posterior pelvic fascial planes, peritoneal reflection, and Denonvilliers' fascia. ${ }^{35}$ With the clear visibility of these features, MRI is important for not only staging the rectal cancer and selecting patients for preoperative neoadjuvant therapy, but to assess resectability and surgical planning as part of the preoperative multidisciplinary discussion. ${ }^{44}$

The blood supply and venous drainage of the rectum correspond to the hindgut embryology; the blood supply is mainly from the superior rectal artery, arising as a main branch from the IMA, and the venous drainage is primarily to the inferior mesenteric vein (IMV) into the portal system. ${ }^{36}$ Veins from the upper two-thirds by the superior rectal vein, which empties into the portal circulation, while veins from the lower third drain into the internal iliac veins and systemic via the middle and inferior rectal veins. The dual venous drainage helps to explain separate patterns of pulmonary and hepatic metastases. ${ }^{45}$ An extensive autonomic nervous system of sympathetic and parasympathetic fibers supplies the rectum and genitourinary tract, controlling continence and sexual function. Knowledge of the anatomy is essential in rectal surgery, as injury to these nerves can lead to incontinence and sexual dysfunction. The sympathetic autonomic plexus arises from T12-L2 lumbar sympathetic nerves, and pass anterior to the aorta and form the superior hypogastric plexus, close to the origin of the IMA. The superior hypogastric plexus enters the pelvis and divides into the left and right hypogastric nerves at the level of the sacral promontory. The hypogastric nerves course posterolateral to the mesorectum and join parasympathetic nerves from the 
pelvis plexus or nervi erigentes to form the inferior hypogastric plexus. The parasympathetic nerves originate from the S2-S4 sacral spinal nerve roots, and run laterally and anteriorly along the mesorectal fascia before joining with the inferior hypogastric nerves to form the inferior hypogastric plexus. The inferior hypogastric plexus is an extensive network with the paired sympathetic hypogastric nerves and parasympathetic pelvic splanchnic nerves on the pelvic sidewall, with the neurovascular bundle extending anterolaterally to the seminal vesicles, distal ureters, vasa deferentia, urinary bladder, prostate and cavernous bodies in men, or lower lateral wall of the vagina in women. ${ }^{46}$ Functionally, the sympathetic autonomous system is responsible for urinary continence and ejaculation. Damage to the sympathetic nerves during ligation of the IMA or during mesorectal mobilization, can lead to urinary incontinence and retrograde ejaculation. The parasympathetic system is responsible for micturition, erection, and lubrication. Damage during the lateral or anterior dissection can lead to difficulty with erection, urinary retention, and issues with sexual lubrication.

\section{TME Technique}

The indication for a TME is curative resection of rectal tumors of the middle and lower thirds of the rectum, either as part of LAR or APR. For mid- to low-rectal cancer, LAR with TME has been demonstrated to minimize locoregional recurrences. ${ }^{27,47,48}$ For upper rectal cancer, or tumors more than $10 \mathrm{~cm}$ from the anal verge, where a distal margin of $5 \mathrm{~cm}$ can be achieved, performing a tumor-specific mesorectal excision, where the mesorectum and the rectum are divided at the same level, is sufficient and is associated with outcomes similar to that achieved with TME. ${ }^{13,48-50} \mathrm{~A}$ complete TME technique is defined as a "complete removal of the lymph node bearing mesorectum along with its intact enveloping fascia." ${ }^{51}$ The three basic principles of the technique were described by Heald as recognition of mobility between tissues of different embryologic origins, sharp dissection under direct vision in good light, and gentle opening of the plane (between the visceral and parietal pelvic fascia) by continuous traction with no actual tearing. ${ }^{24}$ The dissection in this avascular embryologic "holy plane" allows for en bloc removal of the cancer and surrounding mesorectum with an intact mesorectal fascia and preservation of the autonomic nerves. This dissection is performed in a circumferential manner down to the levator muscles to produce a globular, bilobed tissue block produced by the midline indentation posteriorly of the anococcygeal raphe. ${ }^{29}$ The two lobes reflect the paired concavities created by the levator ani muscles. The proof of a properly performed TME is the gross appearance of the specimen itself, which is being increasingly recognized as a reliable predictor of an adequate rectal cancer operation.

Prior to the TME dissection, the surgeon should perform high ligation of the IMA and the IMV, mobilization of the splenic flexure, and division of the colon at the descending sigmoid junction..$^{52}$ The basic components for a TME are sharp dissection in the avascular plane into the pelvis anterior to the presacral fascia and outside the fascia propria or enveloping visceral fascia, division of lymphatic and middle hemorrhoidal vessels anterolaterally, and inclusion of all pelvic fat and lymphatic material at least $2 \mathrm{~cm}$ below the level of the distal margin $(1 \mathrm{~cm}$ for cancers located at or below the mesorectal margin or after neoadjuvant chemoradiotherapy). ${ }^{52}$ The initial step of TME involves finding the "pedicle package," the clue to the top of the "holy plane." The key here is recognition of the shiny fascial-covered surface of the back of the pedicle, found by lifting the sigmoid colon with its mesentery forward to open the plane between the back of the pedicle package and the gonadal vessels, ureter and preaortic sympathetic nerves. Depending on the operative platform, this can be approached by dividing the right leaf of sigmoid mesocolon peritoneum near its root in the midline above the aortic bifurcation (used in laparoscopic and robotic approaches) or in a lateral to medial fashion, as in open surgery, first dividing close to the white lines of congenital adhesions, and then working medially to open the plane. ${ }^{53}$ With the minimally invasive platforms, the pneumoperitoneum can pneumodissect and facilitate opening the retrorectal plane anterior to the presacral fascia for identification of structures at the pelvic brim. A basic principle is that the dissection here should stay on "the yellow side of the white" cobwebs. The combination of forward traction on the visceral package and countertraction on the nerve layer behind allows sharp or diathermy dissection of the areolar tissue to open the plane widely. As the surgeon works upwards in this space, the IMA becomes apparent, and the nerves splitting around it are preserved. The dissection plane is extended downward into the pelvis. The traction drawing the visceral mesorectal envelope away from the autonomic nerve plexuses allows identification of the sympathetic bifurcation-the superior hypogastric plexus-into the paired hypogastric nerves, which course around the mesorectum and down the lateral pelvic sidewalls toward the inferior hypogastric plexus. Dissection is extended downwards anterior to the curve of the sacrum on the surface of the mesorectal fascia. The continued forward traction and countertraction will lift the midline mesorectal pedicle away from the presacral fascia, and facilitate dissection through the angel hair/white areolar plane in the potential space from the perivisceral fascia and parietal presacral fascia. ${ }^{53}$ Dissection should be predominantly from below upwards, allowing the hypogastric nerves to drop away posterolaterally, and should remain in the posterior midline as it descends further into the pelvis, where the visceral fascia on the back of the mesorectum will fall away from the presacral fat and anterior fascia. Performing circumferential mobilization with some dissection in the lateral and anterior planes is recommended rather than proceeding too far posteriorly at this stage. The lateral dissection plane is opened in the same manner, facilitated by retracting the rectum to one side at a time. The dissection is carried down to the level of the levator ani muscle where the two fascial layers fuse together as the rectosacral fascia ligament. This fascial band is ligated and divided to fully open the retrorectal plane and complete the posterior mobilization of the rectum. Posterior and lateral mobilization is easier once the anterior dissection is completed. Anterior mobilization commences in the line of reflection of the visceral peritoneum, where a small incision immediately posterior to the peritoneal reflection will allow entry into the avascular rectovaginal or rectovesical plane. In women, the 
dissection starts with identification of the peritoneum over the pouch of Douglas. Meticulous dissection is necessary to avoid damaging the thin-walled vagina as it is separated from the rectum. In men, dividing the peritoneum just anterior to the fold to avoid entering the rectal wall best enters the plane. The seminal vesicles are identified, and dissection continues in a plane posterior to the seminal vesicles.

In most cases, dissection should remain on the fascia propria in the usual anatomic plane; by not excising Denonvilliers' fascia, postoperative urinary, sexual, and oncologic outcomes will not be affected. However, for anterior tumors, deep dissection anterior to Denonvilliers' fascia of the anterior extraperitoneal rectum is appropriate. ${ }^{40}$ After the completion of the dissection circumferentially, the rectal tube is ready for division. Digital examination is recommended, with or without proctoscopy, to verify the dissection has proceeded past the tumor with appropriate margins for resection. The rectum is divided at the appropriate level. At this level in the low pelvis, there is no further mesorectum, and the rectum is essentially a muscular tube. After division, an anastomosis is created to the rectum either as a straight end-to-end, a small reservoir end-to-side colorectal anastomosis, or as a colonic J-pouch, per the surgeon's preference. In females, special care is taken to distract the rectum from the vagina while stapling to ensure the back wall of the vagina is not accidentally incorporated. Following creation of the anastomosis, an air leak test is performed to validate the integrity of the anastomosis. Per-surgeon preference, a proximal diverting loop ileostomy can be performed.

\section{Beyond TME}

Although TME remains the gold standard for curative rectal resection, recently much attention has been given to further improving oncological results by implementing new techniques. The literature to date shows that much gain can be achieved for the dissection of the most distal third of the rectum, an area with the highest risk of threatening the completeness of the circumferential resection margin. ${ }^{54}$ Quality of the resection and the specimen are mainly determined by maneuverability deep down in the pelvis. In male patients, who require the majority of rectal resections, the mid pelvis is often the narrowest part of the bony structures, resulting in an hourglass-shaped working space (- Fig. 3)..$^{55,56}$

While measuring distances within the bony pelvis gives an impression of access to the pelvic floor, many other factors contribute to reducing the working space, like size of the tumor, volume of the mesorectum, and size of the prostate in male patients. Other factors that contribute to an increasing level of difficulty of low pelvic dissection are high body mass index, time interval after radiotherapy, anterior location of the tumor, and distance between lower border of the tumor and anorectal junction ( - Fig. 4). ${ }^{57,58}$ When all of these factors are present, an optimal dissection is challenging, requiring an expert in rectal cancer surgery, optimally trained in different techniques and performing each on a regular base.

Compared with the traditional open technique, laparoscopy resulted in better short-term outcomes with comparable oncologic results, even in well-trained surgeons. ${ }^{59}$ The

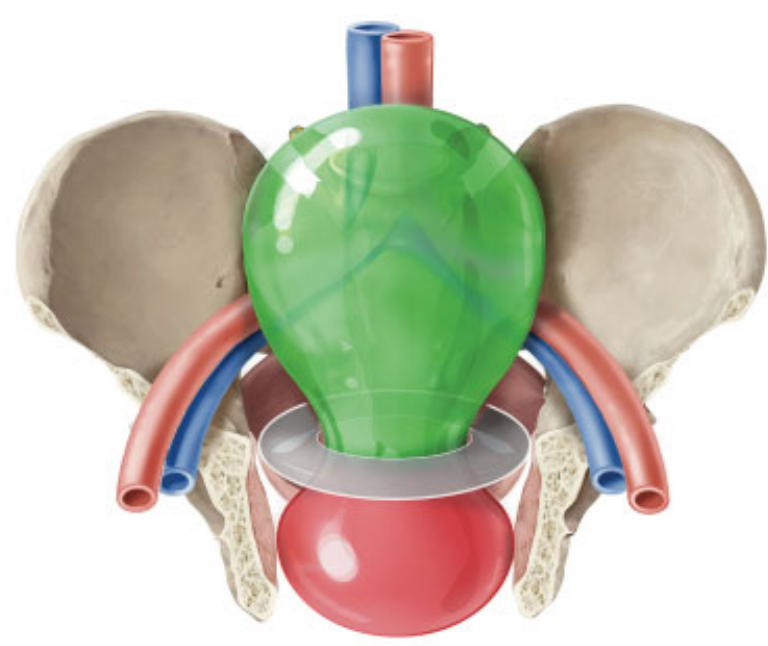

Fig. 3 The hourglass-shaped pelvic working space, with easy (green) and difficult (red) resection planes noted.

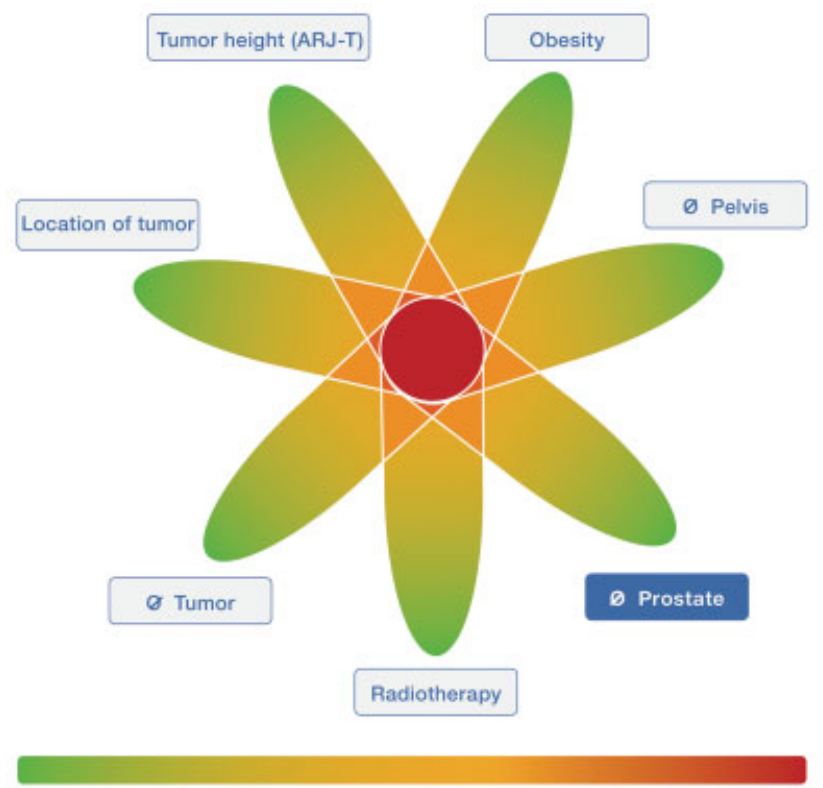

INCREASING LEVEL OF DIFFICULTY

Fig. 4 Factors contributing to increasing levels of difficulty during total mesorectal excision (TME) dissection. RT, radiotherapy.

results from two recently published randomized trials could not demonstrate that laparoscopic rectal cancer surgery was not inferior to open TME when considering a composite pathological endpoint. ${ }^{60,61}$ Although the COREAN and COLOR II trials showed noninferiority when comparing laparoscopic to open TME, this still results in conflicting data with no clear favor for one of the approaches. ${ }^{62,63}$ From a technical point of view there remain some limitations to the laparoscopic approach, mainly related to limitations in articulating instruments and stapler devices. ${ }^{64}$ These limitations and the differences in traction and countertraction required in laparoscopy compared with an open approach implicates a risk to manipulate the tumor site and mesorectum multiple times and to cone into the specimen on the distal rectum, requiring great expertise in more difficult cases (-Fig. 5). Also, the 


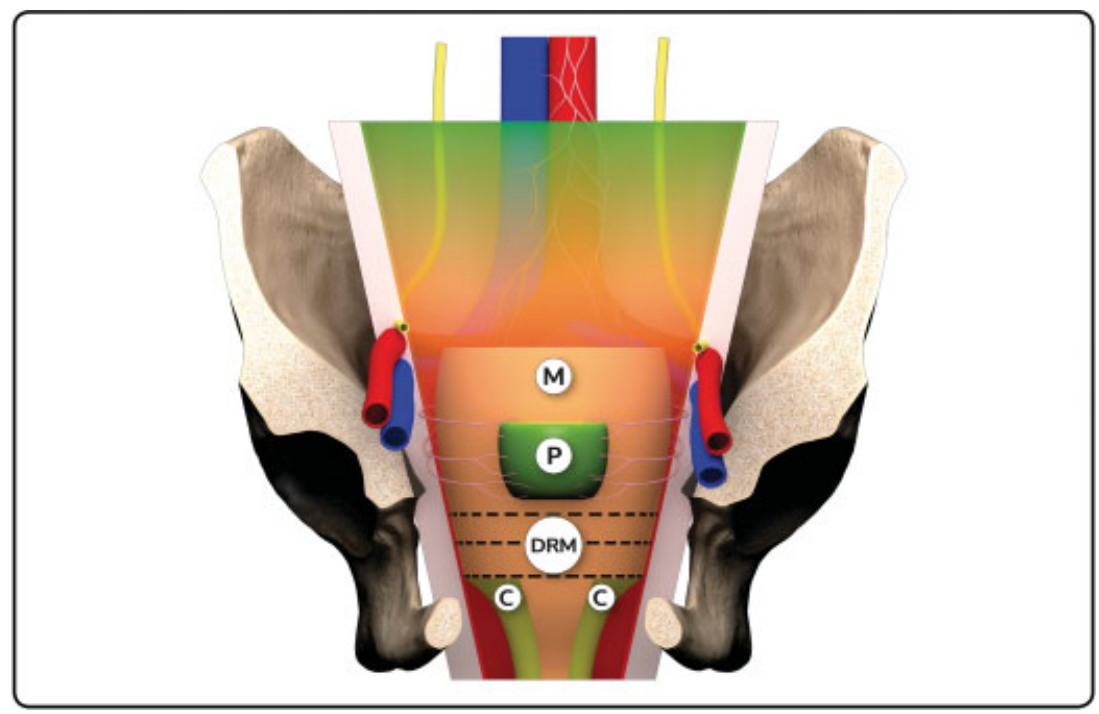

Fig. 5 Three-dimensional (3D) model: Risk of coning (C) into the mesorectum (M) while performing laparoscopic total mesorectal excision (TME) in narrow male pelvis with large prostate (P) (Use VIPicture App).

anterior dissection below the level of the seminal vesicles is hard to visualize when the camera is introduced through an umbilical trocar, as used in a standard setup. The conversion rate of around $10 \%$ reflects the difficulty of the laparoscopic TME procedure. ${ }^{60-63}$

More recently, robotic surgery and transanal surgery have been developed to overcome the limitations of conventional laparoscopic surgery for rectal cancer. Compared with laparoscopic surgery, the robotic system has theoretical advantages of being a stable optic platform, with all moves fully controlled by the surgeon with articulating instruments. These features potentially allow better visualization and maneuverability, even in the lower pelvis, possibly resulting in a better dissection. The anatomical structures are approached as in any other technique from above, with known embryological-derived surgical planes. Difficulties stapling remain an issue, as the robotic stapler reaches a maximum angulation of less than 55 degrees, thus perpendicular stapling of the distal rectum is still difficult in the limited working space. As for all techniques from above, judgment on the DRM is imprecise, and can only be evaluated by a digital rectal exam or the use of a proctoscope before and after introducing the linear stapling device during a robotic procedure. For robotic surgery, there is an ongoing discussion on investment in equipment and costs per procedure, plus time needed for setup and docking. ${ }^{64,65}$ The future launch of different robotic systems might lower the price to make the platform more competitive to costs of conventional laparoscopic surgery. As in all advanced surgical procedures a whole learning curriculum is required with proctoring during first cases and still with a high initial conversion rate. ${ }^{66-68}$ All techniques from above encounter the anatomical structures in a same sequence (in time), and choice between them is mainly based on surgeon's preference, although maneuverability within the pelvis and visualization of structures are important issues.

Transanal TME (taTME) is a recently popularized different concept to treat mid and low rectal cancer. ${ }^{69,70}$ The differ- ence with pure transabdominal techniques is that dissection of the distal third of rectum and mesorectum, the most difficult part of the TME procedure, is performed through the anus. The biggest gain is probably achieved in patients with multiple factors that contribute to an increasing level of difficulty of the pelvic dissection.

The procedure is optimally started by the abdominal team to exclude metastatic pathology and to mobilize the splenic flexure. The patient is secured in the Trendelenburg position, and the abdominal team performs a standardized mobilization of the upper rectum, while a second team can start the transanal portion of the procedure in a synchronized way. After introduction of a rigid or flexible platform into the anus, the level of purse-string suturing should be chosen, considering enough distance to clear the lower border of the tumor. An airtight purse-string suture, washout of the rectal lumen, and recognition of full rectal wall dissection are crucial steps before advancing the perimesorectal dissection in a cylindrical way and toward the team dissecting from above. When both teams connect, traction and countertraction can be optimized, most difficult areas can be tackled together, and the light from the other team can help in recognizing the right plane of dissection. Appreciation of steep angulation during initial posterior dissection, and optimal use of $\mathrm{CO}_{2}$ insufflation are aspects to focus on during initial experience when guided by a proctor. ${ }^{71-73}$

Main benefits of the taTME are better visualization of the anterior part of distal rectal dissection, more precise judgment on DRM, avoidance of imperfect stapling of the distal rectum, and less manipulations of tumor containing rectum and mesorectum. Because taTME differs in many aspects from the transabdominal techniques, a validated training pathway has to be followed, including cognitive and psychomotor skills training. ${ }^{74,75}$ Much attention has to be given on recognition of anatomical structures from below, as well as on pitfalls specifically for the technique; triangles and " $\mathrm{O}$ "'s indicate dissection into a different plane of dissection, while bleeding 
and dissection on bare striated muscle are warning signs of going into a wrong plane. ${ }^{76}$ Specifically in male patients, the urethra is at risk when full-thickness dissection is started below the level of the prostate and aimed too much anteriorly. At the end of the procedure, there is an open rectal stump on which either a purse-string suture and stapling or hand-sewn anastomosis has to be performed. ${ }^{77}$ After completing the training pathway, it is crucial to be proctored during initial experience. Finally, registration of data in a registry is necessary with feedback on individual results for continuous quality improvement with the new approach. ${ }^{78,79}$

\section{Conclusion}

In summary, TME remains the gold standard for curative rectal dissection, but there is room for improvement especially when working space is limited and tumors are advanced. With controversies in the oncologic outcomes of the transabdominal approaches and the cost of robotics for TME, the taTME may be the ideal technique for cases in which multiple factors contribute to a high level of difficulty.

\section{Funding \\ None.}

\section{Conflict of Interest}

None declared.

\section{Acknowledgments}

We acknowledge Stephanie Philippaerts and the iLappSurgery Foundation for the illustrations, 3D animations, and VIP-technology used in this manuscript.

\section{References}

1 Miles WE. A method of performing abdomino-perineal excision for carcinoma of the rectum and of the terminal portion of the pelvic colon. Lancet 1908;2:1812-1813

2 Miles WE. A method of performing abdomino-perineal excision for carcinoma of the rectum and of the terminal portion of the pelvic colon (1908). CA Cancer J Clin 1971;21(06):361-364

3 Miles WE. The radical abdomino-perineal operation for cancer of the pelvic colon. BMJ 1910;11:941-943

4 Miles WE. The present position of the radical abdomino-perineal operation for cancer of the rectum in regard to mortality and postoperative recurrence. Proc R Soc Med 1931;24(07):989-991

5 Moynihan BGA. The surgical treatment of cancer of the sigmoid flexure and rectum with special reference to the principles to be observed. Surg Gynecol Obstet 1908;6:463-468

6 Sanderson ER. Henri Hartmann and the Hartmann operation. Arch Surg 1980;115(06):792-793

7 Dixon CF. Anterior resection for malignant lesions of the upper part of the rectum and lower part of the sigmoid. Ann Surg 1948; 128(03):425-442

8 Bacon HE, Giambalvo GP. Cancer of the rectum; its surgical management without colostomy and with preservation of the internal and external sphincter. J Int Coll Surg 1948;11(05):452-463

9 Black BM. Combined abdominoendorectal resection; technical aspects and indications. AMA Arch Surg 1952;65(03):406-416

10 Habr-Gama A. Indicações e Resultados da Retocolectomia Abdominoendoanal no Tratamento do Câncer de Reto. Sao Paulo: University of Sao Paulo; 1972
11 Campos FG, Habr-Gama A, Nahas SC, Perez RO. Abdominoperineal excision: evolution of a centenary operation. Dis Colon Rectum 2012;55(08):844-853

12 Goligher JC, Dukes CE, Bussey HJ. Local recurrences after sphincter saving excisions for carcinoma of the rectum and rectosigmoid. $\mathrm{Br}$ J Surg 1951;39(155):199-211

13 Monson JR, Weiser MR, Buie WD, et al; Standards Practice Task Force of the American Society of Colon and Rectal Surgeons. Practice parameters for the management of rectal cancer (revised). Dis Colon Rectum 2013;56(05): 535-550

14 Ravitch MM, Steichen FM. Technics of staple suturing in the gastrointestinal tract. Ann Surg 1972;175(06):815-837

15 Fain SN, Patin CS, Morgenstern L. Use of a mechanical suturing apparatus in low colorectal anastomosis. Arch Surg 1975;110 (09):1079-1082

16 Knight CD, Griffen FD. An improved technique for low anterior resection of the rectum using the EEA stapler. Surgery 1980;88 (05):710-714

17 Charpy, Adrien and Poirier, Paul. Appareil digestif. In: Poirier $P$, Charpy A, eds. Traite' d' anatomie humaine. Vol. IV, 2nd ed. Paris: Masson et Cie; 1901:372-373

18 Chapuis P, Bokey L, Fahrer M, Sinclair G, Bogduk N. Mobilization of the rectum: anatomic concepts and the bookshelf revisited. Dis Colon Rectum 2002;45(01):1-8, discussion 8-9

19 Waldeyer W. Das Becken. Bohn: Cohen; 1899

20 Crapp AR, Cuthbertson AM. William Waldeyer and the rectosacral fascia. Surg Gynecol Obstet 1974;138(02):252-256

21 Abel AL. The modern treatment of cancer of the rectum. Milwaukee Proc., March 3-5, 1931: 296-300

22 Heald RJ. A new approach to rectal cancer. Br J Hosp Med 1979;22 (03):277-281

23 Salerno G, Sinnatamby C, Branagan G, Daniels IR, Heald RJ, Moran BJ. Defining the rectum: surgically, radiologically and anatomically. Colorectal Dis 2006;8(Suppl 3):5-9

24 Heald RJ. The 'Holy Plane' of rectal surgery. J R Soc Med 1988;81 (09):503-508

25 Quirke P, Steele R, Monson J, et al; MRC CR07/NCIC-CTG CO16 Trial Investigators; NCRI Colorectal Cancer Study Group. Effect of the plane of surgery achieved on local recurrence in patients with operable rectal cancer: a prospective study using data from the MRC CR07 and NCIC-CTG CO16 randomised clinical trial. Lancet 2009;373(9666):821-828

26 Heald RJ, Santiago I, Pares O, Carvalho C, Figueiredo N. The perfect total mesorectal excision obviates the need for anything else in the management of most rectal cancers. Clin Colon Rectal Surg 2017;30(05):324-332

27 Heald RJ, Ryall RD. Recurrence and survival after total mesorectal excision for rectal cancer. Lancet 1986;1(8496):1479-1482

28 Heald RJ, Karanjia ND. Results of radical surgery for rectal cancer. World J Surg 1992;16(05):848-857

29 Heald RJ, Moran BJ, Ryall RD, Sexton R, MacFarlane JK. Rectal cancer: the Basingstoke experience of total mesorectal excision, 1978-1997. Arch Surg 1998;133(08):894-899

30 Martling AL, Holm T, Rutqvist LE, Moran BJ, Heald RJ, Cedemark B. Effect of a surgical training programme on outcome of rectal cancer in the County of Stockholm. Stockholm Colorectal Cancer Study Group, Basingstoke Bowel Cancer Research Project. Lancet 2000;356(9224):93-96

31 Guren MG, Kørner H, Pfeffer F, et al. Nationwide improvement of rectal cancer treatment outcomes in Norway, 1993-2010. Acta Oncol 2015;54(10):1714-1722

32 Wibe A, Møller B, Norstein J, et al; Norwegian Rectal Cancer Group. A national strategic change in treatment policy for rectal cancer-implementation of total mesorectal excision as routine treatment in Norway. A national audit. Dis Colon Rectum 2002;45 (07):857-866 
33 Kapiteijn E, Putter H, van de Velde CJ; Cooperative investigators of the Dutch ColoRectal Cancer Group. Impact of the introduction and training of total mesorectal excision on recurrence and survival in rectal cancer in The Netherlands. Br J Surg 2002;89 (09):1142-1149

34 Law WL, Chu KW. Impact of total mesorectal excision on the results of surgery of distal rectal cancer. Br J Surg 2001;88(12): 1607-1612

35 Brown G, Kirkham A, Williams GT, et al. High-resolution MRI of the anatomy important in total mesorectal excision of the rectum. AJR Am J Roentgenol 2004;182(02):431-439

36 Heald RJ, Moran BJ. Embryology and anatomy of the rectum. Semin Surg Oncol 1998;15(02):66-71

37 Najarian MM, Belzer GE, Cogbill TH, Mathiason MA. Determination of the peritoneal reflection using intraoperative proctoscopy. Dis Colon Rectum 2004;47(12):2080-2085

38 Heald RJ, Husband EM, Ryall RD. The mesorectum in rectal cancer surgery-the clue to pelvic recurrence? Br J Surg 1982;69(10): 613-616

39 Heald RJ, Moran BJ, Brown G, Daniels IR. Optimal total mesorectal excision for rectal cancer is by dissection in front of Denonvilliers' fascia. Br J Surg 2004;91(01):121-123

40 Lindsey I, Warren BF, Mortensen NJ. Denonvilliers' fascia lies anterior to the fascia propria and rectal dissection plane in total mesorectal excision. Dis Colon Rectum 2005;48(01):37-42

41 Kaiser AM, Ortega AE. Anorectal anatomy. Surg Clin North Am 2002;82(06):1125-1138, v v.

42 Church JM, Raudkivi PJ, Hill GL. The surgical anatomy of the rectum-a review with particular relevance to the hazards of rectal mobilisation. Int J Colorectal Dis 1987;2(03):158-166

43 Nano M, Dal Corso HM, Lanfranco G, Ferronato M, Hornung JP. Contribution to the surgical anatomy of the ligaments of the rectum. Dis Colon Rectum 2000;43(11):1592-1597, discussion 1597-1598

44 Brown G. Thin section MRI in multidisciplinary pre-operative decision making for patients with rectal cancer. $\mathrm{Br} \mathrm{J}$ Radiol 2005; 78(Spec No 2):S117-S127

45 Sakorafas GH, Zouros E, Peros G. Applied vascular anatomy of the colon and rectum: clinical implications for the surgical oncologist. Surg Oncol 2006;15(04):243-255

46 Carmichael JC, Mills S. Anatomy and embryology of the colon, rectum, and anus. In: Steele SR, Hull TL, Read TE, Saclarides TJ, Senagore AJ, Whitlow CB, eds. The ASCRS Textbook of Colon and Rectal Surgery. 3rd ed. New York, NY: Springer; 2016:17

47 McCall JL, Cox MR, Wattchow DA. Analysis of local recurrence rates after surgery alone for rectal cancer. Int J Colorectal Dis 1995;10(03):126-132

48 Tocchi A, Mazzoni G, Lepre L, et al. Total mesorectal excision and low rectal anastomosis for the treatment of rectal cancer and prevention of pelvic recurrences. Arch Surg 2001;136(02): 216-220

49 Leong AF. Selective total mesorectal excision for rectal cancer. Dis Colon Rectum 2000;43(09):1237-1240

50 Hainsworth PJ, Egan MJ, Cunliffe WJ. Evaluation of a policy of total mesorectal excision for rectal and rectosigmoid cancers. Br J Surg 1997;84(05):652-656

51 Trastulli S, Farinella E, Cirocchi R, et al. Robotic resection compared with laparoscopic rectal resection for cancer: systematic review and meta-analysis of short-term outcome. Colorectal Dis 2012;14(04):e134-e156

52 Lichliter WE. Techniques in total mesorectal excision surgery. Clin Colon Rectal Surg 2015;28(01):21-27

53 Chand M, Brown G, Tekkis P, Heald RJ. Total mesorectal excision optimized by pelvic MRI. Colorectal Dis 2014;16(11):847-853

54 Nagtegaal ID, van de Velde CJ, van der Worp E, Kapiteijn E, Quirke P, van Krieken JH; Cooperative Clinical Investigators of the Dutch Colorectal Cancer Group. Macroscopic evaluation of rectal cancer resection specimen: clinical significance of the pathologist in quality control. J Clin Oncol 2002;20(07):1729-1734

55 Creavin B, Kelly ME, Ryan E, Winter DC. Meta-analysis of the impact of surgical approach on the grade of mesorectal excision in rectal cancer. Br J Surg 2017;104(12):1609-1619

56 Akiyoshi T, Kuroyanagi H, Oya M, et al. Factors affecting the difficulty of laparoscopic total mesorectal excision with double stapling technique anastomosis for low rectal cancer. Surgery 2009;146(03):483-489

57 Ferko A, Malý O, Örhalmi J, Dolejš J. CT/MRI pelvimetry as a useful tool when selecting patients with rectal cancer for transanal total mesorectal excision. Surg Endosc 2016;30(03):1164-1171

58 Escal L, Nougaret S, Guiu B, et al. MRI-based score to predict surgical difficulty in patients with rectal cancer. Br J Surg 2018; 105(01):140-146

59 Ohtani H, Tamamori Y, Arimoto Y, Nishiguchi Y, Maeda K, Hirakawa K. A meta-analysis of the short- and long-term results of randomized controlled trials that compared laparoscopyassisted and conventional open surgery for colorectal cancer. J Cancer 2011;2:425-434

60 Stevenson AR, Solomon MJ, Lumley JW, et al; ALaCaRT Investigators. Effect of laparoscopic-assisted resection vs open resection on pathological outcomes in rectal cancer: the ALaCaRT randomized clinical trial. JAMA 2015;314(13):1356-1363

61 Fleshman J, Branda M, Sargent DJ, et al. Effect of laparoscopicassisted resection vs open resection of stage II or III rectal cancer on pathologic outcomes: the ACOSOG Z6051 randomized clinical trial. JAMA 2015;314(13):1346-1355

62 Bonjer HJ, Deijen CL, Abis GA, et al; COLOR II Study Group. A randomized trial of laparoscopic versus open surgery for rectal cancer. N Engl J Med 2015;372(14):1324-1332

63 Jeong SY, Park JW, Nam BH, et al. Open versus laparoscopic surgery for mid-rectal or low-rectal cancer after neoadjuvant chemoradiotherapy (COREAN trial): survival outcomes of an open-label, non-inferiority, randomised controlled trial. Lancet Oncol 2014;15(07):767-774

64 Brannigan AE, De Buck S, Suetens P, Penninckx F, D'Hoore A. Intracorporeal rectal stapling following laparoscopic total mesorectal excision: overcoming a challenge. Surg Endosc 2006;20 (06):952-955

65 Al-Mazrou AM, Chiuzan C, Kiran RP. The robotic approach significantly reduces length of stay after colectomy: a propensity scorematched analysis. Int J Colorectal Dis 2017;32(10):1415-1421

66 Smith R, Patel V, Satava R. Fundamentals of robotic surgery: a course of basic robotic surgery skills based upon a 14-society consensus template of outcomes measures and curriculum development. Int J Med Robot 2014;10(03):379-384

67 Chowriappa AJ, Shi Y, Raza SJ, et al. Development and validation of a composite scoring system for robot-assisted surgical trainingthe Robotic Skills Assessment Score. J Surg Res 2013;185(02): 561-569

68 Jayne D, Pigazzi A, Marshall $\mathrm{H}$, et al. Effect of robotic-assisted vs conventional laparoscopic surgery on risk of conversion to open laparotomy among patients undergoing resection for rectal cancer: the ROLARR randomized clinical trial. JAMA 2017;318(16): $1569-1580$

69 Atallah S, Albert M, Larach S. Transanal minimally invasive surgery: a giant leap forward. Surg Endosc 2010;24(09):2200-2205

70 Sylla P, Rattner DW, Delgado S, Lacy AM. NOTES transanal rectal cancer resection using transanal endoscopic microsurgery and laparoscopic assistance. Surg Endosc 2010;24(05):12051210

71 Knol J, Chadi SA. Transanal total mesorectal excision: technical aspects of approaching the mesorectal plane from below. Minim Invasive Ther Allied Technol 2016;25(05):257-270

72 Knol JJ, D'Hondt M, Souverijns G, Heald B, Vangertruyden G. Transanal endoscopic total mesorectal excision: technical aspects 
of approaching the mesorectal plane from below-a preliminary report. Tech Coloproctol 2015;19(04):221-229

73 Atallah S, Gonzalez P, Chadi S, Hompes R, Knol J. Operative vectors, anatomic distortion, fluid dynamics and the inherent effects of pneumatic insufflation encountered during transanal total mesorectal excision. Tech Coloproctol 2017;21(10):783-794

74 McLemore EC, Harnsberger CR, Broderick RC, et al. Transanal total mesorectal excision (taTME) for rectal cancer: a training pathway. Surg Endosc 2016;30(09):4130-4135

75 Francis N, Penna M, Mackenzie H, Carter F, Hompes R; International TaTME Educational Collaborative Group. Consensus on structured training curriculum for transanal total mesorectal excision (TaTME). Surg Endosc 2017;31(07):2711-2719
76 Bernardi MP, Bloemendaal AL, Albert M, Whiteford M, Stevenson AR, Hompes R. Transanal total mesorectal excision: dissection tips using 'O's and 'triangles'. Tech Coloproctol 2016;20(11):775-778

77 Penna M, Knol JJ, Tuynman JB, Tekkis PP, Mortensen NJ, Hompes R. Four anastomotic techniques following transanal total mesorectal excision (TaTME). Tech Coloproctol 2016;20(03):185-191

78 Penna M, Hompes R, Arnold S, et al; TaTME Registry Collaborative. Transanal total mesorectal excision: international registry results of the first 720 cases. Ann Surg 2017;266(01):111-117

79 Penna M, Hompes R, Arnold S, et al. Incidence and risk factors for anastomotic failure in 1594 patients treated by transanal total mesorectal excision: results from the International TaTME Registry. Ann Surg 2019;269(04):700-711 